\title{
The topography of the mandibular foramen - review of the specialised literature
}

\author{
Topografia găurii mandibulare - trecere în revistă a literaturii de specialitate
}

\author{
Ovidiu Romulus Gherghiță , Vanda Roxana Nimigean², \\ Simona Andreea Moraru ${ }^{2}$, Alexandru Poll ${ }^{3}$, Victor Nimigean ${ }^{3}$ \\ ${ }^{1}$ Facultatea de Medicină Dentară, Universitatea de Medicină şi Farmacie „Carol Davila“, \\ Bucureşti, România \\ ${ }^{2}$ Disciplina Reabilitare Orală, Facultatea de Medicină Dentară, \\ Universitatea de Medicină şi Farmacie „Carol Davila“, Bucureşti, România \\ ${ }^{3}$ Disciplina Anatomie, Facultatea de Medicină Dentară, \\ Universitatea de Medicină şi Farmacie „Carol Davila“, Bucureşti, România
}

\begin{abstract}
The mandibular foramen (MF) is the place for the inferior alveolar nerve anaesthesia. Knowledge of the anatomical landmarks for its location and of the variations regarding its topography is important for the successful treatments of the mandibular teeth.

An analysis of 57 summaries of scientific papers and 41 in extenso articles, using ISI Thomson Web of Knowl-edge, PubMed and MedLine databases, and additionally, a search in 5 anatomy books were performed. The results showed similarities among most of the accessed studies, but also differences. The most frequent variations concerning the MF position were in relation to the vertical plane. According to most authors, the MF is located in the posterior middle third of the anterior-posterior plane of the mandibular ramus. A precise location of the MF provides therapeutic safety and lack of complications.
\end{abstract}

Keywords: mandibular foramen - anatomy, local anesthesia, inferior alveolar nerve

\section{REZUMAT}

Gaura mandibulară (GM) este locul de anestezie pentru nervul alveolar inferior. Cuoaşterea precisă a reperelor anatomice pentru localizarea ei şi a variaţiilor privind topografia acesteia este importantă pentru succesul tratamentelor la nivelul dinţilor mandibulari.

Pentru acest studiu, am analizat 57 rezumate de lucrări ştiinţifice şi 41 de articole integrale, folosind bazele de date ISI Thomson Web of Knowledge, PubMed şi MedLine, iar adiţional am consultat 5 cărţi de anatomie. Rezultatele obţinute au arătat asemănări între cele mai multe studii accesate, dar şi deosebiri. Variaţiile cele mai frecvente, referitoare la poziţia GM, au fost în plan vertical. Conform celor mai mulţi autori, GM este situată în partea posterioară a treimii mijlocii a planului antero-posterior al ramului mandibular.

O localizare precisă a GM conferă siguranţă terapeutică şi lipsa complicaţiilor.

\section{Cuvinte cheie: gaura mandibulară - anatomie, anestezie locală, nervul alveolar inferior}

\section{INTRODUCERE}

Gaura mandibulară (GM) este situată pe suprafața internă a ramului mandibular, fiind flancată anterior de lingula mandibulei, numită frecvent de clinicieni spina Spix, iar posterior de antilingulă. Ea conduce în canalul mandibular vasele şi nervul alveolar inferior. Pentru medicul de medicină dentară, GM reprezintă un reper anatomic important pentru anestezia nervului alveolar inferior $(1,2)$.

Poziția GM este variabilă, fiind influențată de dimensiunile şi de orientarea (înclinarea) ramului mandibular. Acest aspect favorizează scăderea ratei de succes în cazul anesteziei tronculare periferice a nervului alveolar inferior la gaura mandibulară (3).

În aceste condiții, determinarea poziției corecte a găurii mandibulare şi a variaţiilor topografice existente sunt esențiale pentru succesul imediat al 
intervențiilor chirurgicale dento-alveolare de la nivelul zonei posterioare mandibulare.

Cele mai frecvente eşecuri privind anestezia nervului alveolar inferior se datorează localizării incorecte a GM de către clinicieni $(4,5)$.

În literatura de specialitate există multe articole care prezintă succesul anesteziei nervului alveolar inferior la GM, dar încă sunt semnalate eşecuri privind această tehnică de anestezie.

Neglijarea reperelor anatomice, absența unor repere osoase specifice, alături de variațiile privind înclinaţia, lățimea şi înălțimea ramului mandibular pot fi responsabile de eşecul anesteziei nervului alveolar inferior $(3,5,6)$.

Variaţiile privind topografia GM şi prezența găurilor mandibulare accesorii sunt alte motive care influențează rata de succes a anesteziei nervului alveolar inferior $(5,7)$.

Poziția GM prezintă variații între diferitele populații, între diferitele grupe de vârstă din aceeaşi populație şi chiar variații stânga-dreapta la acelaşi individ. Prin urmare, poziția găurii mandibulare ar trebui determinată cu precizie înainte de inițierea oricărei proceduri chirurgicale la nivelul mandibulei (8).

Acest studiu realizează o trecere în revistă a literaturii de specialitate privind topografía găurii mandibulare pentru a clarifica şi identifica reperele anatomice necesare pentru o anestezie precisă şi fiabilă a nervului alveolar inferior, anulând riscurile din cauza variațiilor anatomice loco-regionale.

\section{MATERIAL ŞI METODE}

În cadrul acestui studiu, am efectuat o căutare sistematică în literatura de specialitate pentru a identifica poziția GM față de anumite repere anatomice, marginile ramului mandibular şi creasta oblică internă (creasta temporală). În acest sens, am analizat 57 rezumate de lucrări ştiințifice şi 41 de articole integrale, publicate după anul 2000, utilizând bazele de date ISI Thomson Web of Knowledge, PubMed şi MedLine şi următoarele cuvinte cheie: gaura mandibulară-anatomie, anestezie locală, nervul alveolar inferior. Adițional, am accesat şi 5 cărți de anatomie. Dintre lucrările ştiințifice identifcate, 27 au fost considerate relevante şi au fost incluse în referințele specifice ale aceastui studiu.

\section{REZULTATE ŞI DISCUŢII}

Majoritatea referințelor analizate au raportat distanţele dintre GM şi cele patru margini ale ramului mandibular, dar au existat şi studii, mai puține, care au raportat poziția acestei găuri şi față de creasta oblică internă, unghiul mandibular şi față de molarul trei inferior. Determinările morfometrice privind distanțele dintre reperele mai sus precizate şi GM au fost efectuate în special pe mandibule umane dentate uscate şi mai rar pe radiografii panoramice şi pe imagini mandibulare obținute prin tehnica tomografiei computerizate $\mathrm{cu}$ fascicul conic (CBCT).

Alți autori au determinat distanțele dintre lingula mandibulară şi cele patru margini ale ramului mandibular, arătând importanța cunoaşterii variațiilor morfologice şi morfometrice ale lingulei în localizarea găurii mandibulare $(9,10)$.

Nimigean V. şi colab. (11), analizănd bilateral poziția GM pe 100 mandibule umane dentate uscate, au prezentat următoarele valori medii: $17,1 \mathrm{~mm}$ în stânga şi 16,6 mm în dreapta între GM şi marginea anterioară a ramului mandibular, $9 \mathrm{~mm}$, bilateral, între GM şi marginea posterioară a ramului mandibular, $25 \mathrm{~mm}$ în stânga şi $27 \mathrm{~mm}$ în dreapta între GM şi marginea inferioară a ramului mandibular şi $15,5 \mathrm{~mm}$, bilateral, între GM şi marginea superioară a ramului mandibular. De asemenea, aceşti autori au determinat şi distanța dintre creasta oblică internă şi GM, această distanță având valorile medii de $11 \mathrm{~mm}$ în stânga şi $11,2 \mathrm{~mm}$ în dreapta.

Qudusia S. şi colab. (12) au localizat GM astfel: la $17,69 \pm 2,70 \mathrm{~mm}$ în dreapta şi la $17,94 \pm 2,73 \mathrm{~mm}$ în stânga față de marginea anterioară a ramului mandibular, la $11,39 \pm 1,93 \mathrm{~mm}$ în dreapta şi la $11,40 \pm 2,01 \mathrm{~mm}$ în stânga față de marginea posterioară a ramului mandibular, la $22,90 \pm 3,57 \mathrm{~mm}$ în dreapta şi la 22,39 $\pm 3,18$ mm în stânga față de marginea superioară a ramului mandibular, la $23,87 \pm 4,52 \mathrm{~mm}$ în dreapta şi la $23,66 \pm 4,36 \mathrm{~mm}$ în

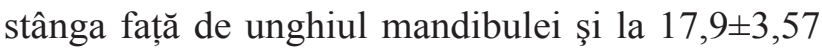
mm în dreapta şi la 17,6 $\pm 3,77$ mm în stânga față de molarul trei, arătând că în clinică rata de succes privind anestezia nervului alveolar inferior nu este foarte ridicată din cauza reperării inexacte a GM de către practicieni.

Prado şi colab. (13) au localizat GM la 19,2 $\pm 3,6$ mm în dreapta şi la $18,8 \pm 3,8$ mm în stânga față de 
marginea anterioară a ramului mandibular, la $14,2 \pm 8,4$ mm în dreapta şi la $13,0 \pm 2,6$ mm în stânga față de marginea posterioară a ramului mandibu-

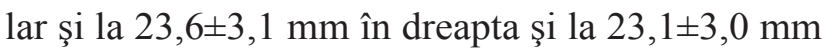
în stânga față de marginea superioară a ramului mandibular.

Padmavathi şi colab. (7) au localizat GM la $16,8 \pm 2,8 \mathrm{~mm}$ în dreapta şi la $16,9 \pm 2,5 \mathrm{~mm}$ în stânga față de marginea anterioară a ramului mandibular, la $11,7 \pm 2,0 \mathrm{~mm}$ în dreapta şi la $12,1 \pm 2,4 \mathrm{~mm}$ în stânga față de marginea posterioară a ramului man-

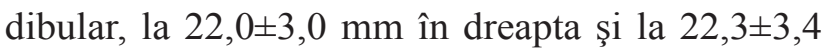
mm în stânga față de marginea superioară a ramului mandibular şi la $22,6 \pm 3,4 \mathrm{~mm}$ în dreapta şi la 22,2 2 2,9 mm în stânga față de unghiul mandibulei.

Khan I.A. şi Ansari M.A. (14) au arătat că GM este localizată la $16,06 \pm 1,99 \mathrm{~mm}$ în dreapta şi la $16,13 \pm 2,10$ mm în stânga față de marginea anterioară a ramului mandibular şi la 12,02 $\pm 1,99 \mathrm{~mm}$ în dreapta şi la $11,10 \pm 1,95$ mm în stânga faţă de marginea posterioară a ramului mandibular. Aceşti autori au precizat că absența reperelor osoase specifice, alături de variațiile privind înălțimea şi lățimea ramului mandibular sunt factori responsabili pentru eşecul anesteziei nervului alveolar inferior.

Ennes J.P. şi Medeiros R.M., (4) au arătat că

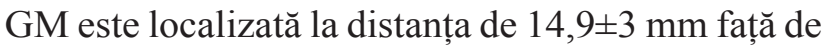
marginea anterioară a ramului mandibular, la dis-

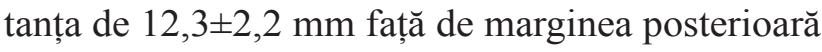
a ramului mandibular, la distanța de $23,5 \pm 2,8 \mathrm{~mm}$ față de marginea superioară a ramului mandibular şi la distanţa de $21 \pm 4,1 \mathrm{~mm}$ față de marginea inferioară a ramului mandibular.

Alți autori au arătat că GM este localizată la $16,9 \pm 1,9$ mm în stânga şi la $16,77 \pm 1,92 \mathrm{~mm}$ în dreapta față de marginea anterioară a ramului man-

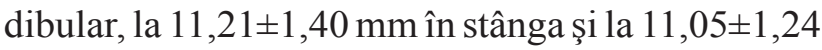
mm în dreapta față de marginea posterioară a ramului mandibular, la $22,93 \pm 3,88 \mathrm{~mm}$ în dreapta şi la $23,15 \pm 3,65$ mm în stânga față de marginea superioară a ramului mandibular, la $21,02 \pm 3,43 \mathrm{~mm}$ în dreapta şi la 21,8 $\pm 3,09$ mm în stânga faţă de unghiul mandibulei şi la distanţa de 22,96 $\pm 3,21 \mathrm{~mm}$ în dreapta şi la $23,64 \pm 3,29$ mm în stânga faţă de marginea inferioară a ramului mandibular (15).

Conform lui Shenoy V şi colab. (16), GM a fost

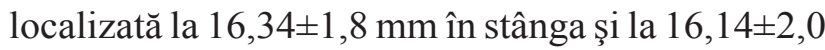
mm în dreapta față de marginea anterioară a ramului mandibular, la $11,68 \pm 2,1 \mathrm{~mm}$ în dreapta şi la
$11,30 \pm 1,9$ mm în stânga față de marginea posterioară a ramului mandibular şi la $23,58 \pm 3,1 \mathrm{~mm}$ în

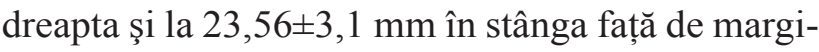
nea superioară a ramului mandibular.

Conform lui Oguz O. şi Bozkir M.G. (17), distanţa dintre GM şi marginea anterioară a ramului mandibular a fost de $16,9 \mathrm{~mm}$ în dreapta şi 16,78 mm în stânga, distanța dintre GM şi marginea posterioară a ramului mandibular a fost de $14,09 \mathrm{~mm}$ în dreapta şi $14,37 \mathrm{~mm}$ în stânga, distanţa dintre GM şi marginea superioară a ramului mandibular a fost de 22,37 mm în dreapta şi 22,17 mm în stânga, iar distanța dintre GM şi marginea inferioară a ramului mandibular a fost de $30,97 \mathrm{~mm}$ în dreapta şi 29,75 mm în stânga.

Alți autori au studiat topografia GM cu ajutorul radiografiilor panoramice. Conform acestor autori localizarea cea mai frecventă a GM a fost în partea posterioară a treimii mijlocii a ramului mandibular în plan antero-posterior, rezultate simetrice bilateral. Aceste rezultate sunt în concordanță cu foarte multe studii care au determinat poziția GM pe mandibule umane uscate şi în contrdicție cu alte studii, mai puține, care au arătat că GM este situată predominant în centrul ramului mandibular $(18,19,20,21)$.

Alţi autori au determinat poziţia găurii mandibulare prin CBCT, motivând că această metodă morfometrică oferă imagini de înaltă rezoluție, în trei dimensiuni ale spaţiului, cu o doză mică de radiaţii şi cu o precizie ridicată. Rezultatele prezentate privind distanţa dintre GM şi marginile ramului mandibular au fost asemănătoare cu majoritatea studiilor menționate anterior, astfel: distanța medie de la GM la marginea anterioară a ramului mandi-

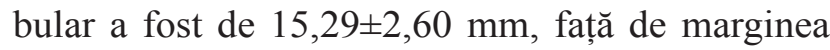
posterioară a fost de $11,13 \pm 2,44 \mathrm{~mm}$, față de marginea superioară a fost de $16,70 \pm 3,75 \mathrm{~mm}$, iar față de marginea inferioară a fost de $24,75 \pm 4,62 \mathrm{~mm}$ $(22,23,24)$.

In plan vertical, am constatat cele mai frecvente variații referitoare la poziția GM, astfel față de marginea superioară a ramului mandibular, distanţa dintre această margine şi GM a prezentat următoarele valori: $15,50 \mathrm{~mm}$ valoarea minimă, $23,60 \mathrm{~mm}$ valoarea maximă şi 19,55 mm valoarea medie. Faţă de marginea inferioară a ramului mandibular, distanţa dintre această margine şi GM a prezentat următoarele valori: $21,02 \mathrm{~mm}$ valoarea minimă, $30,97 \mathrm{~mm}$ valoarea maximă şi $25,99 \mathrm{~mm}$ valoarea medie. 
În plan antero-posterior, variaţiile referitoare la poziția GM au fost mai reduse, astfel față de marginea anterioară a ramului mandibular, distanța dintre această margine şi GM a prezentat următoarele valori: 14,9 mm valoarea minimă, 19,2 mm valoarea maximă şi 17,0 mm valoarea medie. Față de marginea posterioară a ramului mandibular, distanța dintre această margine şi GM a prezentat următoarele valori: $9,0 \mathrm{~mm}$ valoarea minimă, $14,2 \mathrm{~mm}$ valoarea maximă şi $11,6 \mathrm{~mm}$ valoarea medie.

Din totalul referințelor accesate, doar două au raportat GM la creasta oblică internă, rezultatele raportate fiind asemănătoare, 11,2 mm în dreapta şi 11 mm în stânga, între marginea anterioară a găurii mandibulare şi creasta oblică internă, respectiv $13,83 \mathrm{~mm}$ în dreapta şi 13,68 mm în stânga, între mijlocul găurii mandibulare şi creasta oblică internă $(11,5)$.

Considerăm că deşi acest reper osos, creasta oblică internă a mandibulei, a fost neglijat în majoritatea studiilor accesate, el poate fi identificat clinic cu precizie, destul de uşor.

Datorită variațiilor privind topografia GM, unii autori au arătăt că există o rată de eşec destul de mare, de $20-25 \%$, privind anestezia nervului alveolar inferior $(6,7)$.

Localizarea GM prezintă variații considerabile. Aceste variații apar din cauza diferențelor rasiale, a creşterii craniofaciale, a variabilității anatomice şi a metodologiilor utilizate în diferite studii; astfel, în unele studii măsurătorile s-au efectuat de la marginile ramului mandibular la maginile găurii mandibulare, iar în alte studii de la marginile ramului mandibular la centrul găurii mandibulare $(8,25)$.

Există şi autori care au arătat efectul vârstei asupra poziţiei în plan sagital (antero-posterior) a GM. Conform rezultatelor prezentate distanța dintre GM şi marginea anterioară a ramului mandibular se mă- reşte cu vârsta, iar unghiul mandibular se micşorează $(26,27)$.

Alţi autori susţin că topografia găurii mandibulare se modifică după pierderea dinţilor, iar această variabilitate poate fi, de asemenea, responsabilă de eşecul ocazional al anesteziei nervului alveolar inferior (13).

Sunt şi autori care arată că eşecurile în anestezia nervului alveolar inferior se datorează strict erorii medicului şi nu variaţiilor anatomice (5).

Cunoaşterea reperelor anatomice pentru stabilirea cât mai precisă a poziţiei găurii mandibulare şi a variaţiilor topografice posibile este deosebit de importantă pentru succesul anesteziei nervului alveolar inferior.

GM nu este situată în centrul ramului mandibular nici în plan vertical, nici în plan sagital, poziția ei fiind destul de variabilă față de cele patru margini ale ramului mandibular, existând, totuşi, o anumită simetrie dreapta-stânga, simetrie semnalată în majoritatea referințelor parcurse.

\section{CONCLUZII}

Considerăm că cele mai importante repere pentru localizarea clinică a găurii mandibulare sunt creasta oblică internă şi marginea anterioară ale ramului mandibular. Din cauza poziției variabile, gaura mandibulară poate fi considerată un obstacol anatomic pentru anestezia nervului alveolar inferior în medicina dentară.

\section{RECUNOAŞTERE}

Acest studiu face parte din Teza de doctorat a doctorandului Ovidiu Romulus Gherghiță, pentru obținerea titlului ştiinţific de Doctor în Medicină dentară, la Universitatea de Medicină şi Farmacie „Carol Davila“ din Bucureşti.

\section{BIBLIOGRAFIE}

1. Standring S. Gray's Anatomy - The anatomical basis of clinical practice, 40th Edition. Churchill Livingstone, Elsevier, Chicago, 2008.

2. Gopalakrishna K., Deepalaxmi S., Somashekara S.C., Rathna B.S. An anatomical study on the position of mandibular foramen in 100 dry mandibles. Int $J$ Anat Res 2016; 14(1): 1967-71.

3. Nimigean V. Anatomie clinică şi topografică a capului şi gâtului pentru medicina dentară - Note de curs. Ed. Cermaprint, Bucureşti, 2014.

4. Ennes J.P., Medeiros R.M., Grant J.C. Localization of Mandibular Foramen and Clinical Implications. Int J Morphol 2009; 27(4): 1305-11.

5. Thangavelu K, Kannan R, Senthil Kumar N, Rethish E, Sabitha S, Sayeeganesh N. Significance of localization of mandibular foramen in an inferior alveolar nerve block. J Nat Sci Biol Med 2012; 3(2): 156-60.

6. Kanan S., Pratik S., Ajay P. Study of the Location of the Mandibular Foramina in Indian Dry Mandibles. Global Research Analysis 2013; 2(7): 128-30. 
7. Padmavathi G., Suman T., Varalakshmi K.L., Roopashree R. An Anatomical Study of Mandibular and Accessory Mandibular Foramen in Dry Adult Human Mandibles of South Indian Origin. IOSR-JDMS 2014; 13(4): 83-8.

8. Patil K., Guledgud M.V., Bhattacharya P.T. Reliability of Panoramic Radiographs in the Localization of Mandibular Foramen. J. Clin Diag Res 2015; 9(5): 35-8.

9. Srimani P., Goswami B., Mazumdar S. Morphologic and Morphometric Analysis of Lingula in Localizing Mandibular Foramen with its Surgical Importance. International Journal of Anatomy, Radiology and Surgery 2017; 6(4): DOI: 10.7860/ IJARS/2017/27600:2303A001.

10. Monnazzi M.S., Passeri L.A., Gabrielli M.F.R., Bolini P.D.A., de Carvalho W.R.S., da Costa Machado H. Anatomic study of the mandibular foramen, lingula and antilingula in dry mandibles, and its statistical relationship between the true lingula and the antilingula. Int J Oral Maxillofac Surg 2012; 41(1): 74-8.

11. Nimigean V., Măru N., Poll A., Nimigean V.R. Gaura mandibulară - Anatomie clinică. Revista Naţională de Stomatologie 2002; 5(2): 13-5.

12. Qudusia S., Shariff M.H., Ramakrishna A. Study of surgical landmarks of mandibular foramen for inferior alveolar nerve block: An Osteological study. Indian Journal of Clinical Anatomy and Physiology 2016; 3(1): 37-40.

13. Prado F.B., Groppo F.C., Volpato M.C., Caria P.H. Morphological changes in the position of the mandibular foramen in dentate and edentate Brazilian subjects. Clin Anat 2010; 23(4): 394-8.

14. Khan I.A., Ansari M.A. An Anatomical Study and Clinical Correlations of Mandibular Foramen in Dry Adult Human Mandibles of North Indian Origin. Annals of International Medical and Dental Research 2016; 2(4): 161-4.

15. Rajkumari K., Nongthombam S.S., Chongtham R.S., Huidrom S.D., Tharani P., Sanjenbam S.D. A Morphometric Study of the Mandibular Foramen in Dry Adult Human Mandibles. Journal of Dental and Medical Sciences 2017; 16(12): 39-45.

16. Shenoy V., Vijayalakshmi S., Saraswathi P. Osteometric analysis of the mandibular foramen in dry human mandibles. Journal of Clinical and Diagnostic Research 2012; 6(3): 557-60.

17. Oguz O., Bozkir M.G. Evaluation of the location of the mandibular and mental foramina in dry, young, adult human male, dentulous mandibles. West Indian Med J 2002; 51(1): 6-14.

18. Ansari A.S., Ahmed I. Localization of the mandibular foramen on the panoramic radiographs. J Ayub Med Coll Abbottabad 2015; 27(3): 576-9.

19. Peker .I, Gungor K., Semiz M., Tekdemir I. Localization of Mental and Mandibular Foramens on the Conventional and Digital Panoramic Images. Coll Antropol 2009; 33(3): 857-62.

20. Trost O., Kazemi A., Cheynel N., Benkhadra M., Soichot P., Malka G., Trouilloud P. Spatial relationships between lingual nerve and mandibular ramus: original study method, clinical and educational applications. Surg Radiol Anat 2009; 31(6): 447-52.

21. Kilarkaje N., Nayak S.R., Narayan P., Prabhu L.V. The location of the mandibular foramen maintains bilateral symmetry in mandibles of different age groups. Hong Kong Dent J 2005; 2(1): 35-7.

22. Kilic C., Kamburoglu K, Ozen T, Balcioglu HA, Kurt B, Kutoglu T, Ozan H. The Position of the Mandibular Canal and Histologic Feature of the Inferior Alveolar Nerve. Clin Anat 2010; 23(1): 34-42.

23. Kamburoglu K., Kilic C., Ozen T., Yüksel S.P. Measurements of mandibular canal region obtained by cone beam computed tomography: a cadaveric study. Oral Surg Oral Med Oral Pathol Oral Radiol Endod 2009; 107(2): e34-42.

24. Aglarci O.S., Gungor E., Altunsoy M., Nur B., Ok E., Colak M. Three-Dimensional Analysis of Mandibular Foramen Location: A Cone Beam Computed Tomography Study. OMICS J Radiol 2015; 4(1): 179. DOI:10.4172/21677964.1000179.

25. Prajna Paramitha S., Poonam K. Morphometric analysis of mandibular foramina and incidence of accessory mandibular foramina in adult human mandibles of an Indian population. Rev Arg de Anat Clin 2013; 5(2): 60-6.

26. Ashkenazi M., Taubman L., Gavish A. Age-associated changes of the mandibular foramen position in anteroposterior dimension and of the mandibular angle in dry human mandibles. Anat Rec 2011; 294(8): 1319-25.

27. Lipski M., Tomaszewska I.M., Lipska W., Lis G.J., Tomaszewski K.A. The mandible and its foramen: Anatomy, anthropology, embryology and resulting clinical implications. Folia Morphol 2013; 72(4)4: 285-92. 